\title{
Teacher's Abilities of Translation of Symbolic Representation to Visual Representation and Vice Versa: Addition of Integers
}

\author{
Hapizah $^{1}$, Susanti, $\mathbf{E}^{2}$, Astuti, $\mathbf{P}^{3}$ \\ 1,2,3 Universitas Sriwijaya, Indonesia \\ Corresponding email: hapizah@fkip.unsri.ac.id.
}

\begin{abstract}
Translation of representations is a process of changing representations from one into another one. In generally, mathematics representations consists of symbolical, visual (graphical), verbal, and tabular representations. This article discusses results of research about teacher's understanding of mathematics representations and its implementation, which is teacher's ability of translating from symbolical representation to graphical representation and vice versa. The sample of research were 91 mathematics teacher from some districts of South Sumatera and Bangka Belitung provinces. The data of research were collected by test related to addition of integers. The results show that teacher's ability of translating from symbolical representation into graphical representation is very low which is only $48,4 \%$ of the sample could translate the representations correctly, meanwhile teacher's ability of translating from graphical representation into symbolical representation is quite good which is $75,8 \%$ of the sample could translate the representations correctly. The mistakes identified when the mathematics teachers translated symbolic representation to visual representation are the result of addition not presented in numbers line, no the result of addition presented at all, the order of numbers line not presented clearly, misdirection or no direction of numbers line, and no answers at all. Meanwhile the mistakes identified when the mathematics teachers translated visual representation to symbolic representation are no the result of addition presented, incorrectly order of numbers added, and no answers at all.
\end{abstract}

Keywords: Representation;Translation; Symbolic; Visual; Mathematics Teachers

DOI: http://dx.doi.org/10.20961/ijpte.v3i1.19268

Except where otherwise noted, content on this site is licensed under a Creative Commons Attribution 4.0 International License. 


\section{INTRODUCTION}

Mathematics can be represented in many forms such as symbolic, visual, verbal, or tabular representations. Student's abilities of translation of one representation to another one reflect student's understanding of mathematics concepts. Mathematics representations showed by students are expressions of mathematics ideas to understand a mathematics concept or problem and to find solution of the problem (NCTM, 2000). Most teachers and researchers agree with that the key to understand, to communicate, and to operate mathematics concepts effectively is by connecting and translating visual, tabular, symbolical, and verbal representations (Boose, 2011). Translation is a process of changing representations from one into another (Janvier, 1987).

Teachers as one element of teaching and learning have to facilitate their students to achieve good abilities of representations. Zhonghe (2004) says that teachers have to understand and to develop many kinds abilities of representations in order to facilitate students to achieve conceptual understanding, and teachers have to focus on developing transformations of concepts from one representation into other representations. Leinhardt, Zaslavsky, \& Stein (1990) say that teachers must have good skills and knowledge related to mathematics representations. Applying representations effectively by teachers indicates that the teachers have understanding of topics comprehensively. Within interaction between students and teachers, in order to help students to achieve abilities of representations teachers have to understand how their students perceive mathematics representations and how they connect one representation to others (Smith, 2003).

According to Bosse (2011) there are many studies related to investigation of the impact of teacher understanding and the implementation of mathematical representations in the learning towards students' achievement, but few related to examination of the impact of teachers' understanding and the difficulty of learners in translating between mathematical representations. There are many researchers whom argue that the relation between teachers' understanding of mathematical representation and its implementation is inconsistent, but there are also many researchers whom claim the relation is consistent (Bosse, 2011). Teachers whom have understanding of the ability of mathematical representation would be able to translate mathematical representations from one representation to another one.

Mathematical representation is an instrument to see whether learners have mathematical knowledge and mathematical ability (Liu, 2012). It also works for teachers, to see teachers' mathematical knowledge and mathematical ability we need to investigate how teachers' ability of mathematical representations. By designing questions about addition of integers we can assess how teachers' ability of mathematical representations, which are symbolic representation and visual representation.

Symbolic representation focuses on notation of symbols and the use of variables and formulas. There are five common symbolic representations which are 
equations, expressions, algebraic equations, algebraic expressions, and formulas. Symbolic representation is also known as algebraic representation. Graphical representations include factorial, model, horizontal diagrams, vertical diagrams, graphs, and coordinate graphs (Shirley, 2006). The symbolic representation of the sum of two integers is the sum expression, for instance $6+(-8)=-2$. How to translate the sum expression to a visual or graphical representation is by showing the sum and the result on the integer line. This paper specifically discusses teachers' abilities of translation of mathematical representations from symbolic representations to visual representations and vice versa, in case of addition of two integers.

\section{SAMPLE AND TECHNIQUE OF DATA COLLECTION}

The sample of research were total 91 mathematics teachers of junior high school (SMP), senior high school (SMA), and vocational school (SMK) from several districts and cities in South Sumatera and Bangka Belitung. Data were collected by testing the sample of research with questions about addition of two integers in which the mathematics teachers were asked to translate symbolic representation to visual representation and vice versa.

\section{RESULTS AND DISCUSSION}

\section{Teachers' ability of translation of symbolic representation to visual representation}

Teachers' ability of translation of symbolic representation to visual representation could be measured by evaluating teachers' answers of the question as follows "Determine the sum of $6+(-8)$ by the number line". The question looks like very easy to be answered, but in fact many the mathematics teachers gave unclear or even incorrect answers. The mistakes, especially in creating a line to declare -8 , and drawing a line for -2 which is the result of the sum of the two numbers. Total the mathematics teachers whom answered the question correctly is 44 teachers $(48.4 \%)$, and whom answered incorrectly is $51.6 \%$. The details of the teacher's answers are described in Table 1.

The question demands teachers to show process of finding the sum of the two integers by number line. The rules of addition of two numbers expressed by number line are the direction of arrow for positive numbers is right, and the direction of arrow for negative number is left. The order of creating numbers in addition of two numbers by number line is very important to know. Teachers must know and distinguish which one is the first number, the second number, or the result of addition of two numbers. For instance, $6+(-8)=-2$, the first number is 6 , the second number is -8 , and the result of the sum is -2 . Number 6 is expressed by arrows from number 0 to the right (positive) direction of 6 units, and the number (-8) is expressed by arrows from number 6 to the left (negative) direction of 8 units. The last digit indicated by the arrow of the second number is the result of the sum, and it is denoted by the arrow from the original point which is 0 to the last digit which is -2 . 
Table 1. Recapitulation of Teachers' Mistakes of Translation of Symbolic to Visual Representation

\begin{tabular}{llcc}
\hline No. & \multicolumn{1}{c}{ Type of Mistake } & Potal & 10,9 \\
\hline 1 & $\begin{array}{l}\text { Drawing arrows of the first number and the } \\
\text { second number correctly, circling the number } \\
\text { which the result of the sum, but not drawing } \\
\text { the arrow of the result of the sum. }\end{array}$ & 10 & 21,9 \\
\hline $\begin{array}{l}\text { Drawing arrows of the first number and the } \\
\text { second number correctly, but not circling the } \\
\text { number which the result of the sum, nor } \\
\text { drawing the arrow of the result of the sum. }\end{array}$ & 20 & 5,5 \\
\hline $\begin{array}{l}\text { Drawing all arrows of the numbers, but the } \\
\text { order of the numbers added and the result of } \\
\text { the sum were not showed clearly }\end{array}$ & 5 & 2,2 \\
\hline $4 \quad \begin{array}{l}\text { Drawing all arrows of the numbers, but } \\
\text { direction of arrow of result of the sum } \\
\text { incorrectly }\end{array}$ & 2 & 5,5 \\
\hline 5 & $\begin{array}{l}\text { Not giving direction for the numbers added } \\
\text { and the result of the sum }\end{array}$ & 5 & 5,5 \\
\hline 6 & Not giving answers at all & 5 & \\
\hline
\end{tabular}

Table 1 shows that $10.9 \%$ teachers answered the question incorrectly by not drawing the visual representation for the result of the sum. Picture 1 shows the type of mistakes.

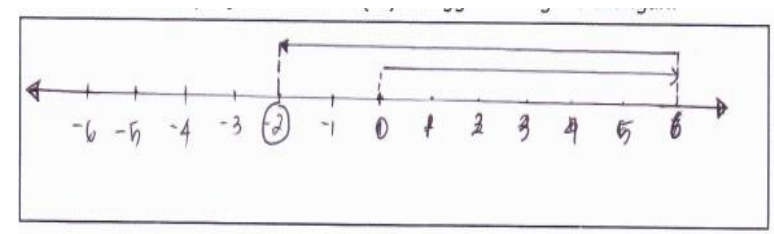

Picture 1. A sample of teacher's mistakes

Picture 1 shows the teacher gave the correct answer in form of mathematics symbolic but gave the incorrect answer in form of visual representation. This finding indicates that the teacher familiar with symbolic representation or algebraic expression only, which is similar to what Monoyiou et al (2007) found in their research.

The most common mistake identified when the teachers translated symbolic representation to visual representation is that they drew the arrows of the two numbers added correctly but they did not identified the sum of the numbers. Picture 2 shows the type of mistakes. 


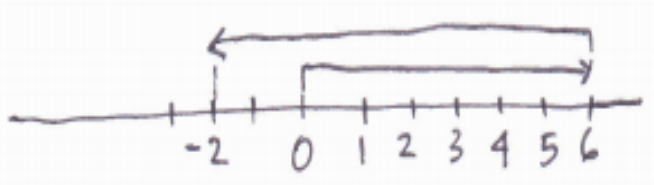

Picture 2. A sample of teacher's mistakes

There are 20 teachers (21.9\%) answering like in Picture 2. This mistake shows that the teachers do not comprehensively understand what the question requires. Actually in order to solve any problem, understanding toward the problem is the most important things (Polya, 1990).

The other mistake identified when the teachers translated symbolic representation to visual representation is that the order of the numbers added and the result of the sum were not showed clearly. There are 5 teachers $(5.5 \%)$ dealing with the mistake. The order of the numbers added and the result of the sum is the important point in form of visual representation, because it will make different meaning of addition of two numbers. The type of mistakes is showed by Picture 3 .

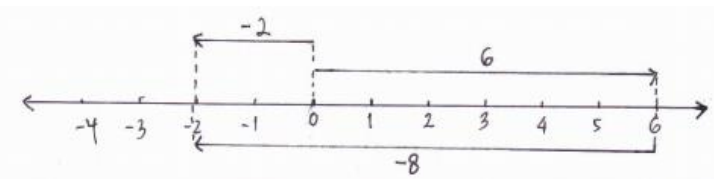

Picture 3. A sample of teacher's mistakes

The answer in Picture 3 is incorrect for answering the question " $6+(-8)$ ", because the answer in Picture 3 has meaning addition of two numbers " $6+(-$ 2)".

The other type of mistakes identified when the teachers translated symbolic representation to visual representation is that they made direction of arrow of result of the sum incorrectly. There are 2 teachers $(2.2 \%)$ dealing with the type of mistakes and Picture 4 shows a sample of the mistakes. We can see in Picture 4 the teacher drew two directions for the arrow of the result of the sum, which is wrong.

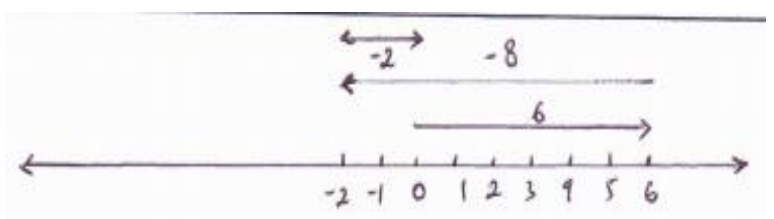

Picture 4. A sample of teacher's mistakes 
The teachers also made another type of mistakes which they did not give direction for the numbers added and the result of the sum. This type of mistakes was made by 5 teachers $(5.5 \%)$. A sample of the mistake is showed by Picture 5.

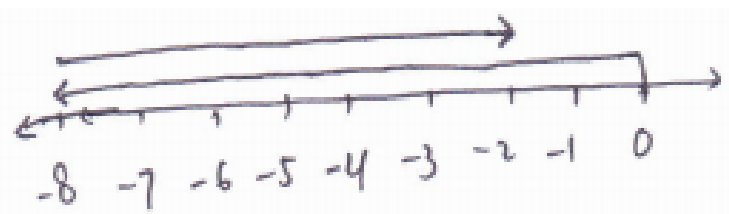

Picture 5. A sample of teacher's mistakes

\section{Teachers' ability of translation of visual representation to symbolic representation}

The question designed to investigate teachers' ability of translation of visual representation to symbolic representation is "State the addition of two numbers and its result showed by picture 6 in form of algebraic expression."

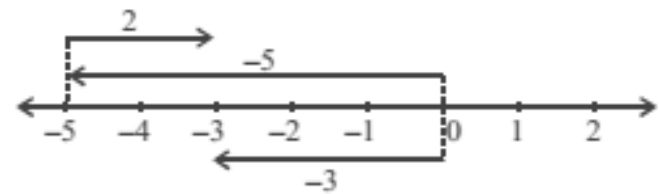

Picture 6. The question of translation visual representation to symbolic representation

The correct answer for the question above is " $(-5)+2=-3$. There are 69 teachers from 91 teachers $(75,8 \%)$ giving the correct answer. and 22 teachers $(24,2 \%)$ answering the question incorrectly. This finding shows that some teachers still have problem in translating visual representation to symbolic representation. The types of mistakes what the teachers made are described in Table 2.

Table 1. Recapitulation of Teachers' Mistakes of Translation of Visual to Symbolic Representation

\begin{tabular}{clcc}
\hline No. & \multicolumn{1}{c}{ Type of Mistake } & Total & Percentage \\
\hline 1 & $\begin{array}{l}\text { Stating the algebraic expression of addition of } \\
\text { two numbers without stating the result of the } \\
\text { sum }\end{array}$ & 6 & $6,6 \%$ \\
\hline 2 & $\begin{array}{l}\text { Stating the algebraic expression with order } \\
\text { the numbers added incorrectly }\end{array}$ & 8 & $8,8 \%$ \\
\hline 3 & $\begin{array}{l}\text { Stating the algebraic expression incorrectly by } \\
\text { mixing all the numbers or no stating at all }\end{array}$ & 8 & $8,8 \%$ \\
\hline
\end{tabular}


The first type of mistakes identified when the teachers translated visual representation to symbolic representation is that the teachers only wrote algebraic expression for the two numbers added without stating the expression for the result of the sum. For instance of the teachers mistakes, the teacher only wrote " $-5+2$ " for symbolizing the addition of two numbers in Picture 6, which should be " $-5+2=3 "$. There are 6 teachers $(10.9 \%)$ whom made this type of mistakes.

The common mistake which many teachers did when symbolizing a visual representation of addition of two numbers is stating the order of numbers added incorrectly. An example of the mistake is that the teacher wrote " $2+(-$ $5)=3$ " for symbolizing visual representation in Picture 6 , which has different meaning and different visual representation with " $-5+2=3$ ". There are 8 teachers $(8.8 \%)$ whom did this type of mistakes when symbolizing all components in Picture 6.

The other type of mistakes identified when teachers symbolized a visual representation of addition of two numbers is that they mixed all the numbers without making any distinction between the numbers added and the result of the sum appropriately. An example of the mistake is that the teachers wrote "($3)+5=2$ " for symbolizing visual representation in Picture 6, which is an incorrect answer. There are 8 teachers $(8.8 \%)$ identified whom did the mistake. Picture 7 shows how a teacher made mistake of translation of visual representation to symbolic representation for Picture 6.

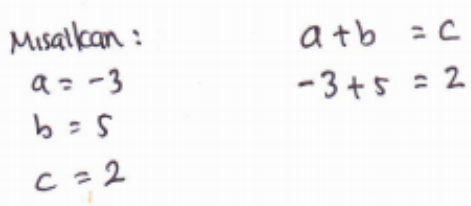

Picture 7. An example of teacher's mistakes of translation of visual to symbolic representation for Picture 6

Based on findings of this research it can be said that teachers' ability of translation of visual (graphic) representation to symbolic representation is already good, because $75,8 \%$ of the teachers could give the correct answer for the questions. It shows that symbolic representation is a representation commonly used by teachers in their teaching and learning. Pinar (2014) also says that teacher students tend to use symbolic representation or algebraic representation, and verbal representation to solve mathematics problems.

\section{CONCLUSION AND RECOMMENDATION}

Based on findings and discussion above, it can be concluded that teachers' ability of translation of symbolic representation to visual representation in case of addition of integers is lower, because only $48.9 \%$ of 91 teachers could perform well. Meanwhile teachers' ability of translation of visual representation to 
symbolic representation in case of addition of integers is good, because $75.8 \%$ of 91 teachers could answer well.

The types of teacher's mistakes identified when the teachers translated symbolic representation to visual representation are the order of the numbers added and the result of the sum not showed clearly; not drawing the visual representation for the result of the sum; drew the arrows of the two numbers added correctly but not identified the sum of the numbers; made direction of arrow of result of the sum incorrectly; and not giving direction of arrows for the numbers added and the result of the sum.

Meanwhile the types of mistakes identified when teachers symbolized a visual representation of addition of two numbers are only wrote algebraic expression for the two numbers added without stating the expression for the result of the sum; and mixed all the numbers without making any distinction between the numbers added and the result of the sum appropriately.

Investigation more deeply about the types of teacher's mistakes has not been done, so it is recommended to do next research to find out why the teachers made the mistakes.

\section{REFERENCES}

Bosse, M., Adu-Gyamfi, K., \& Cheetham, M. (2011). Translations Among Mathematical Representation: Teacher Beliefs and Practices. East Carolina University

Cobb, P., Yackel, E., \& Wood, T. (1992). A Constructivist Alternative to the Representational View of Mind in Mathematics Education. Journal for Research in Mathematics Education, 23(1), 2.

Debrenti, E. (2015). Visual Representations in Mathematics Teaching: An Experiment with Students. Acta Didactica Napocensia, Volume 8 Number 1

Durkaya, M., Özge, E., Fatih, Ö., Kaplan, A., Aksu, Z., Cihan, K. (2011). Preservice mathematics teachers' multiple representation competencies about determinant concept. Procedia Social and Behavioral Sciences 15, 25542558.

Goldin, G. A. (2002). Representation in Mathematical Learning and Problem Solving. In L. D. English (Ed.), Handbook of International Research in Mathematics Education (pp.197-218). Mahwah, New Jersey: Lawrence Erlbaum Associates, Publishers.

Gulkilik, H. \& Arikan, A. (2012). Preservice secondary mathematics teachers' views about using multiple representations in mathematics instruction. Procedia - Social and Behavioral Sciences 47 ( 2012 ) 1751 - 1756.

Hapizah. (2016). Modul Perkuliahan Belajar dan Pembelajaran Matematika. Tidak dipublikasikan

Janvier, C. (1987). Translation process in mathematics education. In C. Janvier (Ed.), Problems of representation in mathematics learning and problem solving (pp. 27-31). Hillsdale, NJ: Lawrence Erlbaum Associates. 
Kar, T., \& Isik, A. (2011). Prospective mathematics teachers abilities' to construct relations between the different representation of series with complex terms. Procedia-Social and Behavioral Sciences Vol 15, pp 356 - 360.

Leinhardt, G., Zaslavsky, O., \& Stein M. K. (1990). Functions, Graphs and Graphing: Tasks, Learning and Teaching. Review of Educational Research, 60(1), 37-42.

Liu., Z. (2012). Survey of Primary Students' Mathematical Representation Statis and Study on the Teaching Model of Mathematical Representation. Journal of Mathematics Education Vol 5. No. 1 pp 63-76.

Monoyiou, A., Papageorgiou, P., \& Gagatsis, A. (2007). Students' and teachers' representations in problem solving. Working Group 1: The role of images and metaphors in the learning and understanding mathematics. CERME 5, 2007, 141-150.

National Council of Teachers of Mathematics (NCTM). (2000). Principles and Standards for School Mathematics. Reston, VA: Author.

Pinar, A. (2014). The Examination of Representation used by Classroom Teacher Candidates in Solving Mathematical Problems. Educational Sciences: Theory \& Practice, 14 (16) pp $2349-2365$.

Smith, S. P. (2003). Representation in school mathematics: Children's representations of problems. In J. Kilpatrick, W. G. Martin \& D. Schifter (Eds.), A research companion to Principles and Standards for School Mathematics (pp. 263-274). Reston, NJ: NCTM.

Zhonghe, W. (2004). The Study of Middle Scholl Teachers' Understanding and Use of Mathematical Representation in Relation to Teachers' Zone of Proximal Development in Teaching Fractions and Algebraic Functions. 
